\title{
IN SITU NUTRIENT SENSORS FOR OCEAN OBSERVING SYSTEMS
}

\author{
Lori Adornato $^{(1)}$, Andres Cardenas-Valencia ${ }^{(1)}$, Eric Kaltenbacher $^{(1)}$, Robert H. Byrne $^{(2)}, \operatorname{Kendra}$ Daly $^{(2)}$, \\ Kate Larkin $^{(3)}$, Sue Hartman ${ }^{(3)}$, Matt Mowlem ${ }^{(3)}$, Ralf D. Prien ${ }^{(4)}$, Veronique Garcon ${ }^{(5)}$ \\ (1) SRI (Stanford Research Institute) International, 450 8th Avenue Southeast, St. Petersburg, FL 33701 USA, \\ Email:lori.adornato@sri.com ; andres.cardenas-valencia@sri.com; eric.kaltenbacher@sri.com \\ (2) University of South Florida, College of Marine Science, 140 7th Avenue South, St. Petersburg, FL 33701 USA, \\ Email: byrne@,marine.usf.edu; kdaly@marine.usf.edu \\ (3) National Oceanography Centre, Waterfront Campus, European Way, Southampton SO14 3ZH United Kingdom, \\ Email: Kate.Larkin@noc.soton.ac.uk; suh@noc.soton.ac.uk; matm@noc.soton.ac.uk \\ (4) Leibniz-Institut für Ostseeforschung Warnemünde, Seestr. 15, 18119 Rostock, Germany, \\ Email: ralf.prien@io-warnemuende.de \\ ${ }^{(5)}$ Laboratoire d'Études en Géophysique et Océanographie Spatiales, 14 Avenue Edouard Belin - 31401 Toulouse \\ Cedex 9, France Email:veronique.garcon@legos.obs-mip.fr
}

\section{ABSTRACT}

New insights into global geochemical cycles can be realized through use of in situ nutrient sensors. Although a number of technological advances have been made, there remain challenges to synoptic, longterm nutrient sensing in marine systems. Resources must be expended to address critical sensor development needs that include reductions in size, cost, power consumption, reagent use, and waste generation, and increases in long-term reliability.
\end{abstract}

\section{INTRODUCTION}

In situ sensors and sensor networks have been identified by international consensus as offering a relatively lowcost solution to the problem of under sampling in the ocean. Long-term in situ biogeochemical sensing in the marine environment is challenging, and is at the edge of what is currently routinely achievable. The ocean is a hostile environment for sensor deployment, operation and maintenance, but high levels of precision and extended endurance are required.

Over the past decade, significant progress has been made in the development of in situ nutrient sensors. Many of these sensors use techniques similar to the spectrophotometric methods favored in laboratory analyses, with notable variations that include ultraviolet (UV) detection, long-path length optical cells, and potentiometric measurements. The challenges in developing in situ nutrient sensors include (1) sampling requirements of the system to be studied, (2) biofouling, (3) power requirements for long-term deployments, and (4) quality control.

As in situ sensors continue to develop and improve, so too will the opportunities to conduct groundbreaking research. In the next decade, the transition of nutrient sensors from research to commercial devices is likely to continue, and a new generation of sensors is likely to emerge. Development of protocols to enable sensor and platform interoperability will be important during this time. The focus of this white paper is to describe the status of nutrient sensor development and current modes of deployment, identify the efforts that should be expended to improve performance and usability, and describe areas where fruitful partnerships may result in a better understanding of biogeochemical systems.

\section{CURRENT TECHNIQUES}

Nutrients commonly measured during field studies include nitrate, nitrite, ammonia, phosphate, silicate, and dissolved organic nitrogen and phosphorus species. Iron, although important in oligotrophic surface waters, may not be routinely measured due to its low $(<1 \mathrm{nM})$ ambient concentration. Oceanographic nutrient measurements are commonly made using traditional, discrete shipboard sampling techniques with subsequent analysis in a shore-based facility. In addition to the risk of sample quality degradation during collection and storage, the maximum number of samples collected during these field studies is controlled by such limitations as the number of bottles on a rosette or sample storage capacity. While in situ techniques obviate many of the difficulties posed by discrete sampling, no one sensor is likely to meet all of the challenges or to be appropriate for every application.

Most in situ nutrient analyzers use wet chemical techniques based on laboratory methods that were developed as long as a century ago [1-5]. Wet chemical analyzers such as NAS-2 (Nutrient Analysis-2), NAS-3, Ecolab, SubChemPak, and ANAIS (Autonomous Nutrient Analyzer In-situ) require the addition of chemical reagents to determine one or multiple nutrients (nitrate, nitrite, phosphate, ammonia, iron) [6 and 7]. Such analyzers exhibit very good accuracy due to the use of onboard standards, which can be analyzed separately from the samples to provide a reference. Independent measures of the samples, standards, and reagents can be used to account for drifts and 
degradation in the optics or in the reagents. However, this technique relies on the maintenance of standards to a fixed value throughout the deployments. Though it is possible to estimate drift in standards by measurement of their concentration on retrieval, performance is improved if degradation in the standards is prevented by inoculation (e.g. with mercuric chloride, or chloroform).

Alternatives to wet chemical sensing techniques include nitrate analysis using UV absorbance [8-10] and surface ammonia measurements using a gas diffusion cell and potentiometric analysis [11]. The UV technique provides a very rapid response and does not require reagents or waste storage; however, sensitivity of the UV method is lower than that of wet chemical techniques. The potentiometric technique uses reagents with low toxicity compared with the standard technique, but use of the potentiometric method is presently limited by its depth rating $(3 \mathrm{~m})$.

Analyses of low nanomolar nutrients found in oligotrophic surface waters may be accomplished through use of long-path length optical cells in combination with standard wet chemical methods [12]. Path length selection relies primarily on the range of concentrations expected, although Beer-Lambert linearity may be extended by monitoring multiple wavelengths in instances where the colored product exhibits Gaussian absorbance characteristics [13]. In the case of the pink azo dye formed during nitrate analysis, the molar absorptivity at the peak absorbance waveband (541 to $543 \mathrm{~nm}$ ) differs from the absoptivity at an offpeak wavelength $(600 \mathrm{~nm})$ by about an order of magnitude (Fig. 1). Absorbances at multiple wavelengths can thus be monitored concurrently to provide measurements over a wide range of concentrations. Using this method, low concentrations would be measured using peak wavelengths and measurements of high-concentrations would use off-peak wavelengths. To employ this technique effectively, the instrument must be calibrated to ensure collected data stay within the linear response range of the sensor (Fig. 1b).

During the Alliance for Coastal Technologies (ACT) Workshop [14], participants compiled a list of qualities that would constitute an ideal in situ nutrient sensor.

The list includes:

- self calibration,

- multiple-analyte capability,

- resistance to biofouling,

- low lifecycle cost,

- excellent reliability,

- real-time data transmission,
- low maintenance, and

- interoperability with other sensors.

Progress has been made toward achieving some of these goals, although biofouling and long-term reliability remain problematic.
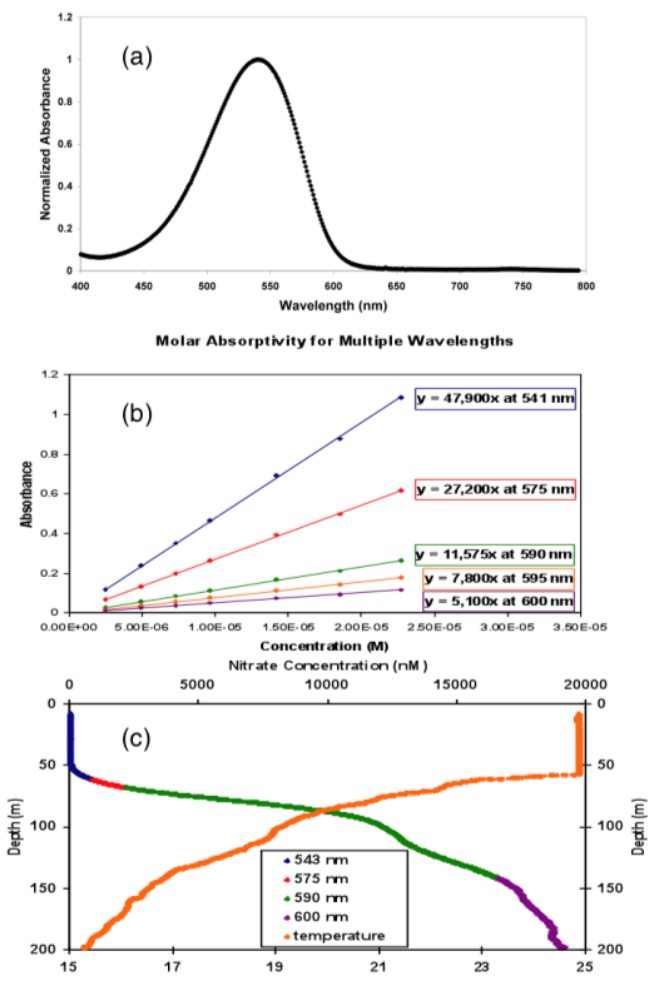

Figure 1. (a) Normalized absorbance spectrum of the azo dye Griess reaction product [13]. (b) Molar absorptivities calculated for $541 \mathrm{~nm}$ (blue), $575 \mathrm{~nm}$ (red), $590 \mathrm{~nm}$ (green), $595 \mathrm{~nm}$ (orange), and $600 \mathrm{~nm}$ (purple) using an HP 8453 diode array spectrometer with $10 \mathrm{~cm}$ optical cell [13]. (c) In situ nitrate profile constructed using a multiple wavelength technique (15 cm path length, SEAS instrument, Gulf of Mexico,

November 2006) and concurrent temperature profile (Falmouth NXIC CTD (Conductivity, Temperature and Depth) [16].

The 2006 ACT (Alliance for Coastal Technologies) Workshop subsequently focused on the use of in situ nutrient sensors on sustained ocean observing systems [15]. While several commercial nutrient sensors have become available and have been fielded, a number of challenges remain. Reagent degradation and storage, as well as waste generation, hamper long-term effectiveness of wet chemical sensors. Development of ink-jet type reagent dispensers may extend deployment life for these devices, and miniaturization of fluidics should reduce waste volume. Additional enhancements 




Figure 2. Hourly nitrate measurements collected with the ISUS (in situ, ultraviolet spectrophotometric sensor) instrument on the MBARI MI(Monterey Bay Aquarium Research Institute) mooring and the same data plotted at three-day, one-week, and two-week intervals show aliasing that can occur when data are under sampled [18].

would include improved ease-of-use and reduction in sensor size and power consumption.

\section{SENSING CHALLENGES}

\subsection{Understanding Requirements}

Nutrient concentration levels often vary by several orders of magnitude between coastal and open ocean regimes, as well as between surface and deep ocean waters. Such variation is frequently beyond the dynamic range of in situ instrumentation [17]. Monitoring subtle nutrient changes in oligotrophic surface waters requires instrumentation with very high sensitivity (Fig. 1), while measuring the general distribution of the same nutrient over full ocean depth does not. Sensors must be capable of sampling with sufficient frequency to avoid aliasing, which can confound analysis of short-term variability (Fig. 2). When sensors are left unattended for extended periods of time, an adaptive sampling strategy may be useful to capture short-term variability during periods when change is known to occur, such as during the spring bloom. For instance, rapid changes in temperature or chlorophyll fluorescence may be used to trigger a change in nutrient sampling frequency. This would require the development of an embedded processing capability that could make "on the fly" sampling decisions.

Aquatic systems with variable salinity or temperature can impact measurement quality due to refractive index changes, alterations in chemical kinetics or efficiencies, and changes in electronic performance that may not be observed in lab-based systems. Characterization of such effects and implementation of methods to remove resultant artifacts are necessary to maintain data integrity. Methods that can be used for colorimetric sensors include monitoring both the dark current and a non-absorbing wavelength to adjust for non-analyte induced optical changes [16].

\subsection{Biofouling}

Methods to preclude or reduce the effects of biofouling become critical when deploying sensors in highly productive coastal regimes or for extended periods of time in the open ocean. Buildup of organisms on instrumentation impacts data quality due to fouling of optical windows, membranes and sensing surfaces; constriction of fluid lines; and creation of microenvironments different from that of the surrounding fluid [19]. A number of approaches have been taken to protect sensors. Mechanical scrapers prove useful on optical surfaces, but can cause abrasion over time. Coatings for sensor surfaces range from nontoxic, short-term barriers (silicone grease) to highly toxic, long-term biocides (tributyltin). Copper coatings, meshes, and shutters are commonly used near sensing surfaces, as they are easy to handle and provide reduced toxicity when compared with tributyltin. Promising new antifouling techniques include biomimetic or bioinspired surfaces and ablative or peel-away coatings [20]. Biofouling remains a significant issue for most if not all sensors used in long-term deployments.

\subsection{Power}

While cabled observatories provide sufficient power to operate sensor networks for extended periods, establishment of the required infrastructure is expensive and by necessity limited in scope. Despite the technology advancements in the development of continuous observing systems, current power sources continue to limit the operational lifetime of systems in the field. The simplest form of in situ sensor power is the packaging of commercial batteries [21]. Secondary or rechargeable batteries such as nickel-cadmium, nickel-metal hydride, and lead acid continue to be used. Water-activated batteries, which have been proposed as a component for flow-induced systems (e.g. semi-fuel cells) are a natural choice for underwater applications, as they are intrinsically pressure compensated and do not need heavy casings - although it is important to avoid interferences between battery effluent and the sensing systems [22 and 23]. Renewable energy systems that utilize various naturally occurring chemicals and conditions in water bodies are options that hold great promise for long-term nutrient sensing, and may include use of (1) methane hydrate fuel cells, (2) microbial fuel cells, (3) sea-surface photovoltaic cells, or (4) motionto-electricity conversion techniques [24-34].

\subsection{Quality Control}

With growing use of in situ nutrient sensors, quality control and calibrations become more important [18]. 
Prerequisite to collection of quality nutrient data are careful laboratory calibrations prior to as well as following instrument deployment. In addition to the in situ calibration method mentioned previously, a number of other quality control measures may be undertaken:

- The effect a certain concentration of analyte would have on the transducer can be simulated by alternative means (e.g. a fluorescence signal could be simulated by a calibrated light source): Signal deterioration due to transducer and electronics drift would be detected with this method, although biofouling effects may go undetected.

- The transducer's response to a certain concentration of analyte can be fed into the signal processing electronics (e.g. adequate signal referencing with respect to a standardized one). This method would not register any changes in the transducer chain prior to the simulated electronic signal.

- As another solution to the growing importance of frequent sensor calibrations, it may be useful to develop systems whose primary function is to perform in situ calibrations on systems that remain at sea for long periods. Nutrient sensors with highquality construction, high precision, and broad dynamic range could be mounted on gliders that are programmed to visit the observation sites of both fixed-site and profiling sensors. The sensors deployed for calibrations could be used for relatively brief intervals and quickly replaced with freshly calibrated systems. Used systems could be renovated and then redeployed for additional missions.

\section{APPLICATION OF SENSORS TO NETWORKS}

Eulerian or fixed-point observatories enable large infrastructure to support numerous, large, and relatively power-hungry sensor payloads with telemetry links to enable real-time data delivery. Across Eulerian observatory networks, the status of biogeochemical sensors and their readiness for use over long deployments is being assessed and improved. One example is EuroSITES, an integrated European network of nine deep-ocean $(>1000 \mathrm{~m})$ Eulerian observatories to observe the hydrographical, biogeochemical, and biological conditions of the eastern North Atlantic Ocean and the Norwegian and Mediterranean Seas. Within the EuroSITES (Integration and enhancement of key existing European deep-ocean observatories) network, a comparison was carried out between nitrate sensors used on long-term fixed-point deployments.

The NAS in situ nutrient sensor, by EnviroTech LLC, provides excellent specificity and precision and is resistant to the effects of bio-fouling and high turbidity. However, specific problems with the NAS have been observed during long-term monitoring in the $\mathrm{M} 3 \mathrm{~A}$
(Mediterranean moored multi-sensor array in the Ligurian, Adriatic, and Cretan Seas) and PAP (Porcupine Abyssal Plain observatory in the eastern North Atlantic Ocean, Fig. 3). The problems include fluidic errors (malfunctioning syringe), and flooding after factory service [35]; such errors are compounded by infrequent service and redeployment intervals (sometimes on the order of one year). Despite this, a three-year nitrate data set has been produced at PAP, showing clear year-to-year variation in winter nitrate at the site (two-year segment shown, Fig. 4) [36 and 37].

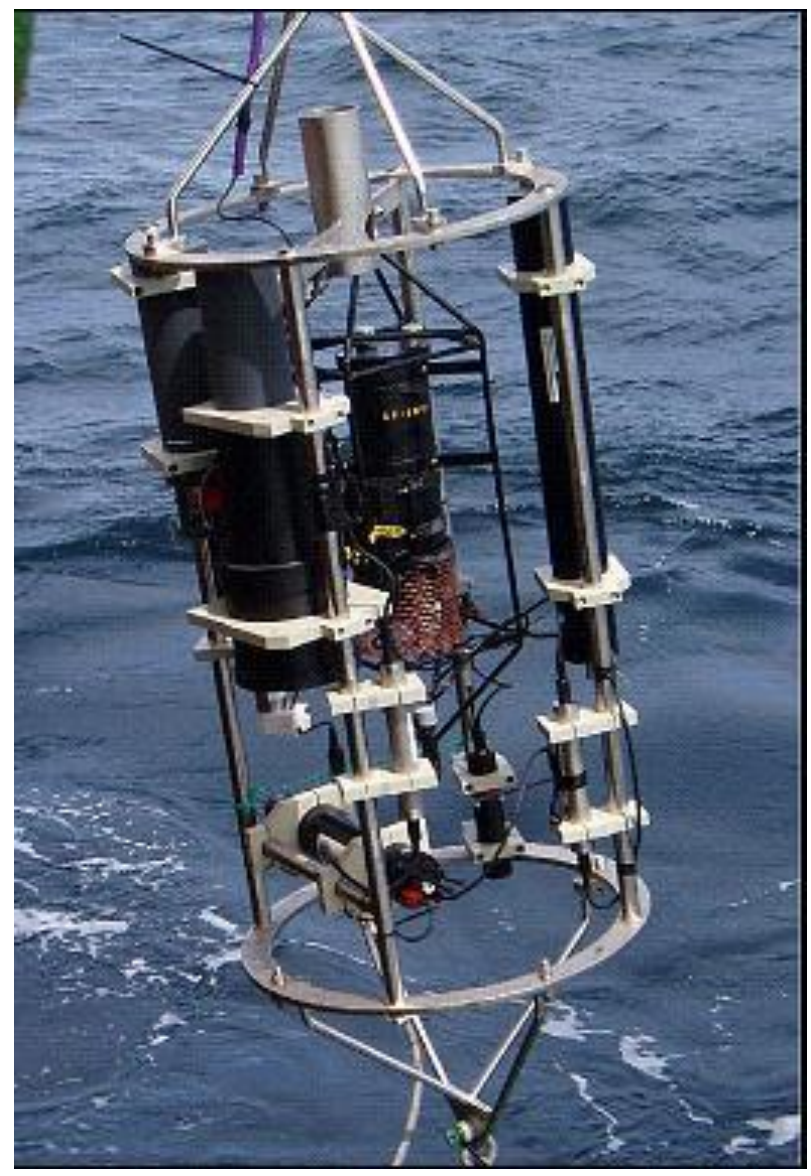

Figure 3. 2007 deployment of the sensor frame at PAP (SBE-37 MicroCAT CTD, HydroScat-2 in situ

fluorometer with copper shutter, SAMI pCO $\mathrm{C}_{2}$ sensor, NAS-2E sensor, and ISUS sensor).

Optical spectrophotometric nitrate sensors (e.g. the ISUS and SUNA (Submersible Ultraviolet Nitrate Analyzer, developed at MBARI and manufactured by Satlantic) improve temporal resolution at fixed-point observatories. These spectrophotometer-based nitrate sensors are promising for use at Eulerian observatories. However, they exhibit some drift and sensitivity to nonnitrate optical changes and are characterized by high detection limits compared with wet chemical analysis for low, open-ocean nitrate concentrations. Detection limits are quoted between $0.5 \square \mathrm{M}$ and $1 \square \mathrm{M}$ with precision of $0.1 \square \mathrm{M}$ [38]. However, a previous six- 
month deployment of the ISUS by Johnson and Coletti [8] suggested a detection limit of $1.5 \square \mathrm{M}$ (compared with $0.1 \square \mathrm{M}$ for the wet chemical NAS). In this particular trial, precision was initially good $(0.5 \square \mathrm{M})$, but was followed by a rapid increase in standard deviation after four months, during which the nitrate measurement became inconsistent and a bias was observed in measurements at low temperatures. Recently published algorithms take account of the lowtemperature bias in the measurements and improve accuracy [39]. The version 3 ISUS upgrade and the smaller SUNA system also promise improved low-level detection. The ISUS has been incorporated into "Apex" floats, which profile to $1000 \mathrm{~m}$. At this depth, biofouling is reduced and a short-term (four-week) precision of $0.1 \square \mathrm{M}$ is possible [40].

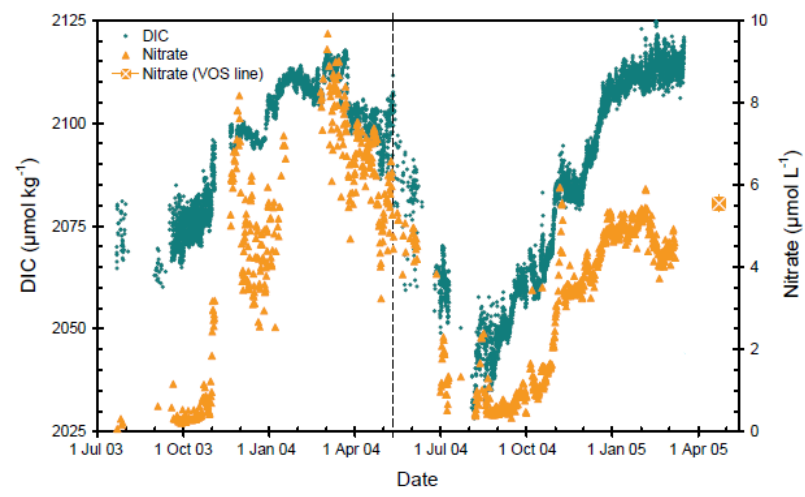

Figure 4. Time series of dissolved inorganic carbon calculated from $\mathrm{pCO}_{2}$ measurements (SAMI pCO sensor) and climatological total alkalinity $\left(A_{T}\right)$, along with nitrate concentrations (Envirotech LLC NAS-2E sensor) in the mixed layer depth at the PAP site in the northeast Atlantic Ocean [36].

\section{THE FUTURE}

\subsection{Miniaturization}

Advances in microsystem technology (MST) including microfabrication, microfluidics, integrated optics and multiphysics analysis have enabled rapid development of MST prototype devices suitable for analysis of nutrients in situ. MST can be used to miniaturize optical and electrochemical nutrient sensors, but has been used most extensively for sensors using reagent-based protocols [41-44]. These systems are examples of "labon-a-chip" (LOC) or micro-total-analysis-systems [45]. Though usually applied to laboratory or point-of-care healthcare applications, the LOC technology offers a number of advantages for in situ nutrient sensors. Microfabrication techniques such as photolithography, laser micromachining, and embossing enable precise construction of structures such as microchannels, mixers and optical elements with dimensions $\sim 50 \mathrm{~mm}$ [46]. Reduction in physical size enables reduced reagent consumption (typically scales as length ${ }^{-2}$ ) as well as (a)

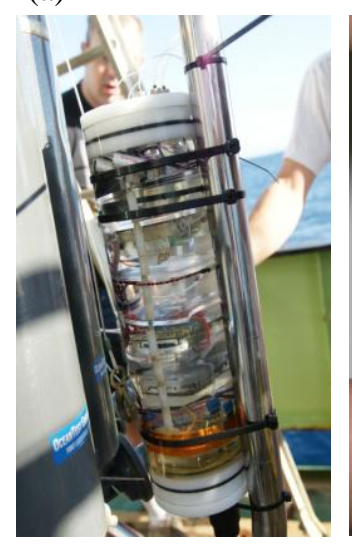

Figure 5. (a) In situ instrument that incorporates an MST nutrient sensor device, and (b) photograph of the MST device (University of Southampton, 2008).

reduced system weight, size, and power consumption. In addition, the Reynolds number of the fluid flow is low (typically <1), resulting in laminar flow and enabling simplified design and analysis. The unit cost of each device can also be significantly reduced, as most MST fabrication techniques are designed for mass production and require very little material.

The application of MST to in situ oceanographic sensing is in its infancy, though survival and operation at depth has been demonstrated [47]. Commercial in situ sensors incorporating MST subsystems and components are now available [48]. In situ nutrient sensing with systems utilizing MST in surface freshwater systems has also been demonstrated [42]. These current systems incorporate MST elements in a system dominated by conventional technology (e.g. pumps, valves, light sources, detectors, batteries, and electronics, as shown in Fig. 5a). The challenge remains to minimize the size of these macro support systems and maximize the functionality of LOC systems. Current in situ devices (see Fig. 5b) integrate fluid channels, junctions, mixers, and optical elements. Future developments could lead to the integration of heaters, valves, pumps, flow sensors, biofouling protection, and functional electrodes in a robust system design. Since a number of industries require micro-fluidic devices, it is possible that a complete MST nutrient sensor may be fieldable in the coming decade, although advances in anti-biofouling remain to be achieved. Similar to macro reagent-based analyzers, LOC systems using reagent-based protocols can attain high levels of accuracy through the use of onboard standards and periodic calibration. Resolution of current systems is typically $100 \mathrm{nM}$, which is sufficient for many studies-but long path absorption cells (see Section 2) and improved detection strategies (e.g. [49 and 50]) could be used to improve this performance. 
The realization of integrated in situ MST nutrient sensor technology, though challenging, promises to deliver high performance, reduced cost, and miniaturized devices. This would enable deployment in large numbers for a wide range of applications (e.g. on Argo (Array for Real-time Geostrophic Oceanography) floats or gliders), allowing nutrient measurements at unprecedented spatial and temporal resolution and extent.

\subsection{New Analytical Methods}

Several analytes, such as dissolved organic nitrogen and phosphorus species, have not yet been successfully measured in situ, since standard analytical protocols are not readily adaptable for use on underwater instrumentation [51-53]. Other analytes, such as iron, are often present at concentrations well below the detection limits of standard spectrophotometric techniques [54]. A benchtop reagentless silicate determination method has been developed based on the electrochemical detection (cyclic voltammetry) of the silicomolybdic complex formed in acidic media by the reaction between silicate and molybdenum salts [55]. The same electrochemical method is being adapted for phosphate determination. When combined with MST, these methods will permit construction of low-power, miniaturized reagentless silicate and phosphate sensors. Development of new methods and instruments to address nutrient sensing challenges will greatly enhance scientific understanding of biogeochemical cycling in marine systems over the next decade.

\subsection{Interoperability}

Future oceanographic nutrient monitoring will benefit from a standardized methodology for sensor design and data exchange. The resulting interoperable sensors and instrumentation are key to providing a broader interpretation of measured data and understanding environmental processes. The concept of sensor networks for oceanographic applications has been discussed since at least the mid 1990s, but is only now developing into an international standard for sensor connectivity. The Open Geospatial Consortium $\left(\mathrm{OGC}^{\circledR}\right)$ has developed standards for connecting sensors to a global information infrastructure [56]. The Sensor Web Enablement (SWE) standards define interfaces and protocols for accessing all types of sensors over the Web. The SWE standards consist of seven main elements:

1. Observations and Measurements: Protocol for encoding measurements.

2. Sensor Model Language: Programming for defining sensors and how they behave.

3. Transducer Markup Language: Method for data transfer and fusion among multiple domains.
4. Sensor Observation Service: Web service for polling and manipulating sensor data.

5. Sensor Planning Service: Web service for sensor control and reconfiguration.

6. Sensor Alert Service: Web service for outputting and responding to sensor alerts.

7. Web Notification Service: Web service facilitating publishing of geospatial processes.

While the complete standard has not been demonstrated, examples of Sensor Web implementation include Sensors Anywhere, a European-based project, and the Integrated Ocean Observing System, in the United States. While OGC SWE is not the sole standard for sensor network, it appears to be the most prevalent and sustainable of standards presently available.

\subsection{Widespread Use of Nutrient Sensors on Observing System Platforms}

Nutrient data are required for a wide range of applications such as ecosystem and hypoxic zone modelling studies, but global coverage is currently inadequate [57]. In particular, nutrient boundary conditions for spring bloom initiation are poorly constrained [58]. It is desirable, therefore, to install nutrient sensors on the widest possible range of platforms in order to collect nutrient and, in particular, nitrate data with high spatial and temporal coverage. In addition to the Eulerian observatories mentioned previously, a number of other platforms are potentially available for sensor deployment. Lagrangian or quasiLagrangian platforms such as Autonomous Profiling Explorer (APEX) floats used in the Argo program provide good global coverage over extended time periods, but since the floats are not serviced after deployment or recovered at the end of their lifespan, sensor payloads must be low-power, robust, selfcalibrating and relatively inexpensive. Gliders and longrange autonomous unmanned vehicles (AUVs) are promising platforms. The Micro-AUV Ready Chemical Analyzer (MARCHEM, SubChem Systems) ammonia sensor has been tested on a REMUS AUV, but due to sensor size and power constraints, deployments of this type are not yet commonplace [59]. Remote moored observatories will require hardened instruments that can be operational for at least a year and have internal calibrations to account for drift and/or biofouling. Since mooring profilers typically travel 0.1 to $0.7 \mathrm{~m} / \mathrm{s}$, nutrient sensors must have optimized sampling rates to provide relatively high-resolution vertical profile measurements. Collaborations between the academic science community and industry in sensor and platform development will accelerate the availability of new technology that can be applied to studying ocean processes. Significant resources must continue to be invested (1) to reduce size, cost, power requirements, 
and reagent use while improving reliability and longterm accuracy of nutrient sensors; and (2) to routinely incorporate them into the full range of ocean observing systems.

\subsection{Government/Academic/Industry Partnerships}

The coming decade will witness a rapid growth in ocean observatories with moored, cabled, and mobile platforms used to investigate a spectrum of basic processes that must be addressed through continuous interdisciplinary experiments. The North-East Pacific Undersea Networked Experiments (NEPTUNE, Canada/US), Victoria Experimental Network Under the Sea (VENUS, Canada), Monterey Accelerated Research System (MARS, US), Advanced Real-Time Earth monitoring Network in the Area (ARENA, Japan), and the European Seafloor Observatory Network (ESONET, Europe) are examples of observatory projects that are contemplated or currently under way [60-62]. The US Integrated Ocean Observing System (IOOS) represents a national partnership in which 17 federal agencies and 11 regional associations share responsibility for the design, operation, and improvement of a national network of observations. The Ocean Observatories Initiative (OOI) is the National Science Foundation's contribution to IOOS. The OOI anticipates completion of planning and starting construction on the observatory infrastructure in 2009. As OOI sensors and platform technologies mature, they may be transitioned to the IOOS array or other observatories.

\subsection{Benefit to Society and Education}

Since nutrients are key variables in oceanic primary production, they affect a wide spectrum of biogeochemical processes. Scientists, resource managers, and policy makers will greatly benefit from installation of nutrient sensors in global ocean observing systems. Data products can be used to predict bloom events, understand processes in remote regions, assess the ocean carbon budget, and support fisheries and ecosystem management efforts. Studies into the effects of global climate change will require nutrient data to monitor and predict global trends in productivity.

Even people who live far inland are fascinated by the ocean. Images and data obtained from observatories can spark the public's curiosity about the oceans through targeted outreach programs. The OOI implementing organizations plan to develop user-friendly data visualization for scientists, as well as visualizations appropriate for students and the public. The Sensor Web concept provides another mechanism to facilitate education. Other targeted materials can be developed for formal and informal education. The goal is to provide the public with a sense of connection to the ocean, and to inspire and motivate students to learn about Earth processes and technology.

\section{ACKNOWLEDGMENTS}

This work was partially supported by grants to the University of South Florida from the Office of Naval Research under contracts N00014-96-1-5011 and N00014-02-0823 (L.A., E.K., and R.H.B.). We acknowledge the support of EU funding through EUROCEANS (European network of excellence for OCean Ecosystems Analysis) network of excellence and through EUROSITES ocean observatory network.

\section{REFERENCES}

1. Hanson, A.K. \& Moore, C. (2001). Real-Time Nutrient Surveys in Coastal Waters. Sea Technology 42(9), 1014.

2. Griess, P. (1879). Bemerkungen zu der Abhandlung der HH. Weselsky und Benedikt Ueber einige Azoverbindungen. Berichte der deutschen chemischen Gesellschaft 12(1), 426-428.

3. Atkins, W.R.G. (1923). The phosphate content of fresh and salt waters in its relationship to the growth of the algal plankton. Journal of the Marine Biological Association of the United Kingdom 13(1), 119-150. doi:10.1017/S002531540001095X.

4. Diénert, F. \& Wandenbulcke, F. (1923). Sur le dosage de la silice dans les eaux. Comptes Rendus Séances de l'Académie des Sciences 176, 1226-1229.

5. Johnson, K.S., Beehler, C.L. \& Sakamoto-Arnold, C.M. (1986). A submersible flow analysis system. Analytica Chimica Acta 179, 245-257. doi:10.1016/S00032670(00)84469-4 |.

6. Hanson, A.K., (2000) A new in situ chemical analyzer for mapping coastal nutrient distributions in real time. Paper presented at the OCEANS 2000 MTS/IEEE Conference and Exhibition, Providence, RI, USA 11 Sep 2000 - 14 Sep 2000 doi:10.1109/OCEANS.2000.882229.

7. Thouron, D., Vuillemin, R., Philippon, X., Lourenco, A., Provost, C., Cruzado, A. \& Garcon, V. (2003). An Autonomous Nutrient Analyzer for Oceanic Long-Term in Situ Biogeochemical Monitoring. Analytical Chemistry 75(11), 2601-2609. doi:10.1021/ac020696+.

8. Johnson, K.S. \& Coletti, L.J. (2002). In situ ultraviolet spectrophotometry for high resolution and long-term monitoring of nitrate, bromide and bisulfide in the ocean. Deep Sea Research Part I: Oceanographic Research Papers 49(7), 1291-1305. doi:10.1016/S09670637(02)00020-1.

9. Finch, M.S., Hydes, D.J., Clayson, C.H., Bernhard, W., Dakin, J. \& Gwilliam, P. (1998). A low power ultra violet spectrophotometer for measurement of nitrate in seawater: introduction, calibration and initial sea trials. Analytica Chimica Acta 377(2-3), 167-177. doi:10.1016/S0003-2670(98)00616-3.

10. Zielinski, O., Fiedler, B., Heuermann, R., Kortzinger, A., Kopiske, E., Meinecke, G. \& Munderloh, K. (2007). A new nitrate continuous observation sensor for autonomous sub-surface applications: Technical design 
and first results. Paper presented at the OCEANS 2007 Europe, Aberdeen, UK.

doi:10.1109/OCEANSE.2007.4302300.

11. Plant, J.N., Johnson, K.S., Needoba, J.A. \& Coletti, L.J. (2009). NH4-Digiscan: an in situ and laboratory ammonium analyzer for estuarine, coastal and shelf waters. Limnol. Oceanogr. Methods 7, 144-156.

12. Adornato, L.R., Kaltenbacher, E.A., Villareal, T.A. \& Byrne, R.H. (2005). Continuous in situ determinations of nitrite at nanomolar concentrations. Deep Sea Research Part I: Oceanographic Research Papers 52(3), 543-551. doi:10.1016/j.dsr.2004.11.008.

13. Adornato, L.R., Kaltenbacher, E.A., Greenhow, D.R. \& Byrne, R.H. (2007). High-Resolution In Situ Analysis of Nitrate and Phosphate in the Oligotrophic Ocean. Environmental Science \& Technology 41(11), 40454052. doi:10.1021/es0700855.

14. State of Technology in the Development and Application of Nutrient Sensors, (2003). (Alliance for Coastal Technologies), Savannah, Georgia, pp. 18, http://www.actus.info/download/workshop_reports/ACT_WR0302_Nutrients.pdf.

15. Recent Developments in In Situ Nutrient Sensors: Applications and Future Directions, (2007). (Alliance for Coastal Technologies), Savannah, Georgia, pp. 26,

http://www.act-

us.info/download/workshop_reports/ACT_WR0608_InSituNutrientsII.pdf.

16. Adornato, L., Kaltenbacher, E.A., Byrne, R.H., Liu, X. \& Easley, R. (2008). High-resolution chemical sensor for unattended underwater networks. Paper presented at the Unmanned/Unattended Sensors and Sensor Networks V, SPIE, Cardiff, Wales, 16 October 2008. doi:10.1117/12.802616.

17. Daly, K.L., Byrne, R.H., Dickson, A.G., Gallager, S.M., Perry, M.J. \& Tivey, M.K. (2004). Chemical and biological sensors for time-series research: current status and new directions. Marine Technology Society Journal 38(2), 121-143.

18. Prien, R.D. (2007). The future of chemical in situ sensors. Marine Chemistry 107(3), 422-432. doi:10.1016/j.marchem.2007.01.014.

19. Whelan, A. \& Regan, F. (2006). Antifouling strategies for marine and riverine sensors. Journal of Environmental Monitoring 8, 880 - 886. doi:10.1039/b603289c.

20. Ralston, E. \& Swain, G. (2009). Bioinspiration-the solution for biofouling control? Bioinspiration \& Biomimetics 4, 9pp. doi:10.1088/1748-3182/4/1/015007.

21. Pucker, L.E. (1952). Fiftieth Anniversary: The Anniversary Issue on Primary Cell Systems. Journal of The Electrochemical Society 99(8), 203C-204C.

22. Cardenas-Valencia, A.M., Biver, C.J., Bumgarner, J. \& Langebrake, L., (2007) Novel, MEMS-fabricated, reserve, galvanic cells for deployable underwater sensors: depth-sensitive activation and in-situ generation of electron-ecceptors species. Paper presented at the SensorComm 2007 International Conference on Sensor Technologies and Applications Valencia, Spain.

23. Cardenas-Valencia, A.M., Adornato, L., Short, R.T. \& Langebrake, L. (2008). Novel enhancement of thinform-factor galvanic cells: Probing halogenated organic oxidizers and metal anodes. Journal of Power Sources 184(1), 318-324. doi:10.1016/j.jpowsour.2008.06.026.

24. Carapezza, E.M. \& Molter, T.M. (2007). Renewable energy for sustainable ocean sensors and platforms. Paper presented at the Unmanned/Unattended Sensors and Sensor Networks IV, SPIE, Florence, Italy. doi: $10.1117 / 12.753481$.

25. Reimers, C., Tender, L.M., Fertig, S. \& Wang, W. (2001). Harvesting Energy from the Marine Sediment-Water Interface. Environmental Science \& Technology 35(1), 192-195. doi:10.1021/es001223s.

26. Reimers, C.E., Girguis, P., Stecher, H.A., Tender, L.M., Ryckelynck, N. \& Whaling, P. (2006). Microbial fuel cell energy from an ocean cold seep. Geobiology 4(2), 123-136. doi:10.1111/j.1472-4669.2006.00071.x.

27. Tender, L.M., Reimers, C.E., Stecher, H.A., Holmes, D.E., Bond, D.R., Lowy, D.A., Pilobello, K., Fertig, S.J. \& Lovley, D.R. (2002). Harnessing microbially generated power on the seafloor. Nat Biotech 20(8), 821-825. doi:10.1038/nbt716.

28. Chaudhuri, S.K. \& Lovley, D.R. (2003). Electricity generation by direct oxidation of glucose in mediatorless microbial fuel cells. Nat Biotech 21(10), 1229-1232. doi:10.1038/nbt867.

29. Blidberg, D., Mupparapu, S., Chappell, S., Komerska, R., Jalbert, J.C. \& Nitzelm, R. (2005). The SAUV II (solar powered AUV) test results 2004. Paper presented at the Oceans 2005 - Europe. doi:10.1109/OCEANSE.2005.1511773.

30. Real-time Environmental Coastal Observations Network (RECON) Project (2006). Ruberg, S.A. \& Brandt, S.B. Last Accessed: 31 March 2009 http://www.glerl.noaa.gov/res/Task_rpts/2002/cmbrandt 13-3.html.

31. Pelrine, R., Kornbluh, R.D., Eckerle, J., Jeuck, P., Oh, S., Pei, Q. \& Stanford, S. (2001). Dielectric elastomers: generator mode fundamentals and applications. Paper presented at the Smart Structures and Materials 2001: Electroactive Polymer Actuators and Devices, SPIE, Newport Beach, CA, USA, 4 March 2001. doi: $10.1117 / 12.432640$.

32. Kim, Y.-H., Oh, J.-S. \& Komatsu, T. (2008). Analysis and design of a wave energy conversion Buoy. Paper presented at the International Offshore and Polar Engineering Conference, International Journal of Offshore and Polar Engineering (IJOPE), Vancouver, BC, Canada, July 6-11, 2008. doi:10.1007/BF03177458.

33. Ponta, F.L. \& Jacovkis, P.M. (2008). Marine-current power generation by diffuser-augmented floating hydro- 
turbines. Renewable Energy 33(4), 665-673. doi:10.1016/j.renene.2007.04.008.

34. Roddier, D., Cermelli, C. \& Aubault, A. (2007). Electrical power generation by tidal flow acceleration. Paper presented at the 26th International Conference on Offshore Mechanics and Arctic Engineering, The American Society of Mechanical Engineers (ASME International), San Diego, California, USA, June 10-15, 2007. doi:10.1115/OMAE2007-29413.

35. Intercomparison of biogeochemical sensors at ocean observatories, Mowlem, M., Hartman, S., Harrison, S. \& Larkin, K.E., (2008). EurOceans Research \& Consultancy Report. 44 pp. 45 , http://www.whoi.edu/cms/files/EUROCEANS_SensorIntercomparisonReport_39645.pdf.

36. Körtzinger, A., Send, U., Lampitt, R.S., Hartman, S., Wallace, D.W.R., Karstensen, J., Villagarcia, M.G., Llinás, O. \& DeGrandpre, M.D. (2008). The seasonal $\mathrm{pCO} 2$ cycle at $49^{\circ} \mathrm{N} / 16.5^{\circ} \mathrm{W}$ in the northeastern Atlantic Ocean and what it tells us about biological productivity. J. Geophys. Res. 113, C04020. doi:10.1029/2007JC004347.

37. Hartman, S.E., Larkin, K.E., Lampitt, R.S., Lankhorst, M. \& Hydes, D.J. (2010). Seasonal and inter-annual biogeochemical variations at $\mathrm{PAP}\left(49^{\circ} \mathrm{N}, 16.5^{\circ} \mathrm{W}\right) 2003$ 2005 associated with winter mixing and surface circulation. Deep-Sea Research II 57(15), 1303-1312. doi:10.1016/j.dsr2.2010.01.007.

38. Johnson, K.S., Coletti, L.J. \& Chavez, F.P. (2006). Diel nitrate cycles observed with in situ sensors predict monthly and annual new production. Deep Sea Research Part I: Oceanographic Research Papers 53(3), 561-573. doi:10.1016/j.dsr.2005.12.004.

39. Sakamoto, C.M., Johnson, K.S. \& Coletti, L.J. (2009). Improved algorithm for the computation of nitrate concentrations in seawater using an in situ ultraviolet spectrophotometer. Limnol. Oceanogr.: Methods 7, 132143.

40. Johnson, K.S., Berelson, W.M., Boss, E.S., Chase, Z., Claustre, H., Emerson, S.R., Gruber, N., Körtzinger, A., Perry, M.J. \& Riser, S.C. (2009). Observing Biogeochemical Cycles at Global Scales with Profiling Floats and Gliders. Oceanography 22(3), 216-225.

41. Fujii, S., Tokuyama, T., Abo, M. \& Okubo, A. (2004). Fluorometric determination of sulrite and nitrite in aqueous samples using a novel detection unit of a microfluidic device. Anal. Sci. 20(1), 209-212. doi:10.2116/analsci.20.209.

42. McGraw, C.M., Stitzel, S.E., Cleary, J., Slater, C. \& Diamond, D. (2007). Autonomous microfluidic system for phosphate detection. Talanta 71(3), 1180-1185. doi:10.1016/j.talanta.2006.06.011.

43. Mowlem, M., Benazzi, G., Holmes, D., Morgan, H., Haas, C., Kraft, M., Taberham, A., Chavagnac, V., Statham, P.J. \& Burkill, P., (2006) Micro System Technology for Marine Measurement. Paper presented at the Oceans 06, Boston, MA, USA, 21 September. doi:10.1109/OCEANS.2006.306823.
44. Provin, C., Fukuba, T., Fujii, T. \& Ieee, (2008) Integrated in situ analyzer for manganese (IISA-Mn) for deep sea environment. Paper presented at the International Conference OCEANS 2008 and MTS/IEEE Kobe Techno-Ocean '08, Ieee, Kobe, JAPAN, Apr 08-11. doi:10.1109/UT.2007.370816.

45. West, J., Becker, M., Tombrink, S. \& Manz, A. (2008). Micro total analysis systems: Latest achievements. Anal. Chem. 80(12), 4403-4419. doi:10.1021/ac800680j.

46. Becker, H. \& Gartner, C. (2000). Polymer microfabrication methods for microfluidic analytical applications. Electrophoresis 21(1), 12-26. doi:10.1002/(SICI)1522-2683(20000101)21:1<12::AIDELPS12>3.0.CO;2-7.

47. Mowlem, M., Sieben, V., Floquet, C., Waugh, E., Taberham, A. \& Morgan, H. (2009). Deep sea nutrient sensing with Lab on a chip technology. IEEE Sensors Journal 9(7), 862-869.

48. Egli, P.J., Hanson, A.K., Moore, C., Dickey, T.D. \& Chang, G.C. (2005). In Situ Phosphate Measurements Aboard the Santa Barbara Channel CHARM Mooring. Paper presented at the American Society of Limnology and Oceanography, Santiago de Compostela, Spain, June 19-24.

49. Gong, W.D., Kraft, M., Mowlem, M. \& Morgan, H. (2008). A Simple, Low Cost Double Beam Spectrophotometer for Colorimetric Detection of Nitrite in Seawater. IEEE Sensors 9(7), 862-869. doi:10.1109/JSEN.2009.2020659.

50. O'Toole, M., Lau, K.T., Shepherd, R., Slater, C. \& Diamond, D. (2007). Determination of phosphate using a highly sensitive paired emitter-detector diode photometric flow detector. Anal. Chim. Acta 597(2), 290-294. doi:10.1016/j.aca.2007.06.048.

51. Collos, Y. \& Mornet, F. (1993). Automated procedure for determination of dissolved organic nitrogen and phosphorus in aquatic environments. Marine Biology 116(4), 685-688. doi:10.1007/BF00355485.

52. Pan, X., Sanders, R., Tappin, A.D., Worsfold, P.J. \& Achterberg, E.P. (2005). Simultaneous Determination of Dissolved Organic Carbon and Total Dissolved Nitrogen on a Coupled High-Temperature Combustion Total Organic Carbon-Nitrogen Chemiluminescence Detection (HTC TOC-NCD) System. Journal of Automated Methods and Management in Chemistry 2005(4), 240246. doi:10.1155/JAMMC.2005.240.

53. D'Elia, C.F., Steudler, P.A. \& Corwin, N. (1977). Determination of Total Nitrogen in Aqueous Samples Using Persulfate Digestion. Limnology and Oceanography 22(4), 760-764.

54. Bowie, A.R., Achterberg, E.P., Croot, P.L., de Baar, H.J.W., Laan, P., Moffett, J.W., Ussher, S. \& Worsfold, P.J. (2006). A community-wide intercomparison exercise for the determination of dissolved iron in seawater. Marine Chemistry 98(1), 81-99. doi:10.1016/j.marchem.2005.07.002. 
55. Lacombe, M., Garçon, V., Comtat, M., Oriol, L., Sudre, J., Thouron, D., Le Bris, N. \& Provost, C. (2007). Silicate determination in sea water: Toward a reagentless electrochemical method. Marine Chemistry 106(3-4), 489-497. doi:10.1016/j.marchem.2007.05.002.

56. OpenGIS® Standards and Specifications (2009). Last Accessed: 29 April 2009 http://www.opengeospatial.org/standards.

57. Justic, D., Rabalais, N.N. \& Turner, R.E. (2003). Simulated responses of the Gulf of Mexico hypoxia to variations in climate and anthropogenic nutrient loading. Journal of Marine Systems 42(3-4), 115-126. doi:10.1016/S0924-7963(03)00070-8.

58. Baretta, J.W., Baretta-Bekker, J.G. \& Ruardij, P. (1998). Data needs for ecosystem modelling. ICES J. Mar. Sci. 55(4), 756-766. doi:10.1006/jmsc.1998.0378.

59. Morin, E., Hanson, A.K., Veitch, S., Egli, P., Donaghay, P., Moore, C. \& Arrieta, R. (2006). Transitioning Submersible Chemical Analyzer Technologies for Sustained, Autonomous Observations from Profiling Moorings, Gliders and other AUVs. Paper presented at the Ocean Sci. Meet. Suppl., Eos Trans. AGU 87(36).

60. Dawe, T.C., Bird, L., Talkovic, M., Brekke, K., Osborne, D.J. \& Etchemendy, S., (2005) Operational Support of Regional Cabled Observatories The MARS Facility. Paper presented at the OCEANS, 2005. Proceedings of MTS/IEEE. doi:10.1109/OCEANS.2005.1639906.

61. Barnes, C.R., Best, M.M.R., Bornhold, B.D., Juniper, S.K., Pirenne, B. \& Phibbs, P., (2007) The NEPTUNE Project - a cabled ocean observatory in the NE Pacific: Overview, challenges and scientific objectives for the installation and operation of Stage I in Canadian waters. Paper presented at the Symposium on Underwater Technology and Workshop on Scientific Use of Submarine Cables and Related Technologies, 2007. doi:10.1109/UT.2007.370809.

62. Priede, I.G., Solan, M., Mienert, J., Person, R., Van Weering, T.C.E., Pfannkuche, O., O'Neill, N., Tselepides, A., Thomsen, L., Favali, P., Gasparoni, F., Zitellini, N., Millot, A., Gerber, H.W., De Miranda, J.M.A., Klages, M. \& Sigray, P., (2004) ESONET European Sea Floor Observatory Network. Paper presented at the OCEANS '04. MTTS/IEEE TECHNOOCEAN'04. doi:10.1109/OCEANS.2004.1406479. 